\title{
Outcome Assessment After Surgical Treatment of Tuberculum Sellae Meningiomas-A Preliminary Report
}

\author{
Arkadiusz WILK ${ }^{1}$, Grzegorz ZIELIŃSKI ${ }^{1}$, Przemysław WITEK², Andrzej KOZIARSKI ${ }^{1}$ \\ ${ }^{1}$ Military Medical Institute, Department of Neurosurgery, Warsaw, Poland \\ ${ }^{2}$ Military Medical Institute, Department of Endocrinology and Isotope Therapy, Warsaw, Poland
}

\section{ABSTRACT}

AIM: To evaluate the endocrinological and ophthalmological results of the tuberculum sellae meningioma surgery.

MATERIAL and METHODS: A total of 18 patients diagnosed with tuberculum sellae meningioma received surgical treatment at Neurosurgery Clinic at Military Medical Institute in Warsaw from January 2010 to July 2012. This analyzed group of patients included 15 females and 3 males at a mean age of 50.5 years (ranging from 30 to 73; SD \pm 13.4 ). In the pre-operative and post-operative periods, all patients underwent magnetic resonance imaging of the head according to a uniform protocol, eye examinations with assessment of visual acuity and field of vision, as well as endocrine tests to evaluate the hypothalamic-pituitary axis (including urine specific gravity and osmolality as well as blood cortisol, TSH, fT3, and fT4 levels). All patients underwent surgical treatment of the tumor via unilateral subfrontal craniotomy, achieving macroscopically complete tumor removal (Simpson grade II resection).

RESULTS: The use of the unilateral subfrontal approach helped improve vision in $88 \%$ of the treated patients. Endocrine tests revealed no hypothalamic-pituitary axis dysfunction. The most commonly diagnosed meningiomas of the area were meningothelial $(77 \%)$ and transitional (12\%) meningiomas.

CONCLUSION: Surgical treatment of tuberculum sellae meningiomas via the unilateral subfrontal approach is a safe technique with no significant complications. Visual improvement was observed in $88 \%$ of the patients who had received this treatment. There were no hormonal disturbances in patients operated via the subfrontal approach either prior to or after the procedure, which suggests that surgical treatment of tuberculum sellae meningiomas has no effect on pituitary endocrine function.

KEYWORDS: Tuberculum sellae meningioma, Frontal craniotomy, Pituitary hormones

\section{INTRODUCTION}

$\mathrm{T}$ Tuberculum sellae meningiomas constitute $5-10 \%$ of intracranial meningiomas $(12,25)$. Their location in the parasellar region, in close vicinity to hypothalamic structures and anterior vessels of the circle of Willis, results in the characteristic clinical signs. This location is also the reason for surgical treatment challenges. The most commonly used approach is the fronto-temporal, or pterional approach; with the fronto-orbital, fronto-orbitozygomatic, frontolateral (unilateral subfrontal), and bifrontal approaches being used less often $(4,5,10,17,23,30,31)$.
We present the outcomes of tuberculum sellae meningioma surgery conducted by a single neurosurgeon, with a particular focus on visual disturbances and hypothalamic-pituitary function $(21,22)$.

\section{MATERIAL and METHODS}

A total of 18 patients diagnosed with tuberculum sellae meningioma were treated surgically at the Neurosurgery Department between January 2010 and July 2012. The study group consisted of 15 females and 3 males at the mean age of 50.5 years (ranging from 30 to 73 years; SD \pm 13.4 ). Table I presents demographic characteristics of the patients. 


\section{Clinical assessment}

None of the evaluated patients were found to have hypothalamic endocrine dysfunction in the pre-operative period. All patients had visual disturbances in the form of reduced visual acuity and/or limited field of vision, including two patients (2 females) reporting only impaired visual acuity and two others (a female and a male) reporting only visual field defects. The history of these visual disturbances ranged from 1 to 36 months (mean: 14 months). Four patients additionally reported headaches in the pre-operative period.
Table II presents clinical data of the evaluated group.

\section{Assessment of visual disturbances}

A uniform protocol was followed to evaluate visual acuity and field of vision (the latter via Goldmann visual field exam) in all patients in the pre- and post-operative period.

\section{Neuroradiological assessment}

All patients underwent magnetic resonance imaging (MRI) assessments pre-operatively and in the post-operative period (3-4 months after surgery). These assessments were

Table I: Sex, Age, and Standard Deviation (SD) Values in the Operated Patients

\begin{tabular}{cccccccc}
\hline & Sex & No. of patients & Mean age & Minimum & Maximum & SD & 73 \\
\hline Age (years) & F & 15 & 48 & 30 & 46 & 14 \\
\hline Age (years) & M & 3 & 54 & 46 & 10 & 65 \\
\hline
\end{tabular}

M: Male, F: Female.

Table II: Pre-Operative Signs and Symptoms in Patients Qualified for Surgery

\begin{tabular}{|c|c|c|c|c|c|c|c|c|c|c|c|}
\hline \multirow{3}{*}{$\begin{array}{l}\text { Pt } \\
\text { No. }\end{array}$} & \multirow{3}{*}{$\begin{array}{c}\mathrm{Pt} \\
\text { initials }\end{array}$} & \multirow{3}{*}{ Age } & \multirow{3}{*}{ Sex } & \multicolumn{8}{|c|}{ Signs and symptoms } \\
\hline & & & & \multirow[b]{2}{*}{ Headache } & \multicolumn{3}{|c|}{ Visual disturbances } & \multicolumn{3}{|c|}{ Pituitary endocrine function } & \multirow{2}{*}{$\begin{array}{c}\text { Tumor } \\
\text { size in } \\
\text { mm } \\
\text { (MRI) }\end{array}$} \\
\hline & & & & & Acuity & $\begin{array}{l}\text { Field of } \\
\text { vision }\end{array}$ & $\begin{array}{l}\text { History of visual } \\
\text { disturbances } \\
\text { (in months) }\end{array}$ & $\begin{array}{l}\text { Diabetes } \\
\text { insipidus }\end{array}$ & $\begin{array}{l}\text { Corticotropic } \\
\text { function }\end{array}$ & $\begin{array}{l}\text { Thyreotropic } \\
\text { function }\end{array}$ & \\
\hline 1. & LS & 45 & $\mathrm{~F}$ & 0 & 1 & 1 & 12 & 0 & 0 & 0 & $20 \times 20 \times 26$ \\
\hline 2. & WJ & 67 & $\mathrm{~F}$ & 1 & 1 & 1 & 1 & 0 & 0 & 0 & $35 \times 30 \times 34$ \\
\hline 3. & IJ & 73 & $\mathrm{~F}$ & 1 & 1 & 1 & 18 & 0 & 0 & 0 & $23 \times 24 \times 36$ \\
\hline 4. & IB & 37 & $\mathrm{~F}$ & 1 & 1 & 0 & 4 & 0 & 0 & 0 & $20 \times 20 \times 20$ \\
\hline 5. & BT & 65 & $\mathrm{~F}$ & 0 & 1 & 1 & 24 & 0 & 0 & 0 & $34 \times 30 \times 20$ \\
\hline 6. & $A D$ & 56 & $\mathrm{~F}$ & 0 & 1 & 0 & 36 & 0 & 0 & 0 & $27 \times 22 \times 28$ \\
\hline 7. & $\mathrm{JP}$ & 67 & $\mathrm{~F}$ & 0 & 1 & 1 & 8 & 0 & 0 & 0 & $35 \times 27 \times 25$ \\
\hline 8. & $W Ł$ & 55 & $\mathrm{~F}$ & 0 & 1 & 1 & 4 & 0 & 0 & 0 & $16 \times 16 \times 8$ \\
\hline 9. & LT & 46 & $\mathrm{M}$ & 0 & 0 & 1 & 24 & 0 & 0 & 0 & $12 \times 10 \times 13$ \\
\hline 10. & EK & 30 & $\mathrm{~F}$ & 0 & 1 & 1 & 6 & 0 & 0 & 0 & $22 \times 26 \times 20$ \\
\hline 11. & $\mathrm{KL}$ & 40 & $\mathrm{~F}$ & 0 & 0 & 1 & 24 & 0 & 0 & 0 & $18 \times 19 \times 14$ \\
\hline 12. & $\mathrm{RP}$ & 52 & $\mathrm{M}$ & 0 & 1 & 1 & 18 & 0 & 0 & 0 & $26 \times 26 \times 24$ \\
\hline 13. & IT & 36 & $\mathrm{~F}$ & 0 & 1 & 1 & 1 & 0 & 0 & 0 & $23 \times 21 \times 12$ \\
\hline 14. & $\mathrm{JP}$ & 57 & $\mathrm{~F}$ & 0 & 1 & 1 & 6 & 0 & 0 & 0 & $15 \times 23 \times 20$ \\
\hline 15. & $\mathrm{JK}$ & 40 & $\mathrm{~F}$ & 0 & 1 & 1 & 36 & 0 & 0 & 0 & $25 \times 25 \times 25$ \\
\hline 16. & 10 & 65 & M & 0 & 1 & 1 & 12 & 0 & 0 & 0 & $35 \times 21 \times 25$ \\
\hline 17. & MW & 31 & $\mathrm{~F}$ & 1 & 1 & 1 & 12 & 0 & 0 & 0 & $18 \times 14 \times 19$ \\
\hline 18. & US & 47 & $\mathrm{~F}$ & 0 & 1 & 1 & 12 & 0 & 0 & 0 & $27 \times 24 \times 24$ \\
\hline
\end{tabular}

Headaches: $0=$ no; $1=$ yes; Visual acuity disturbances: $0=$ no; $1=$ yes; Limited field of vision: $0=$ no; $1=$ yes; Pituitary function: $0=$ normal; 1 = abnormal. Pt: Patient, M: Male, F: Female, MRI: Magnetic resonance imaging. 
conducted at Medical Radiology Laboratory with a Signa 1.5 T scanner (GE Medical Systems) with spin echo (SE) T1-weighted sequences (parameters: Repetition time (TR) $=450-600 \mathrm{~ms}$, Echo time $(T E)=15-30 \mathrm{~ms}$, three excitations, minimum matrix size of $256 \times 256$, field of view approximately $20 \mathrm{~cm}$, slice thickness $2-3 \mathrm{~mm}$ in the coronal and sagittal planes, before and after intravenous administration of the paramagnetic contrast agent gadolinium DTPA (Gd-DTPA), as well as T2-weighted sequences in coronal sections

(Di Chro-Nelson formula);

The pre-operative assessments included:

1) Tumor size,

2) Possible concomitant cerebral edema,

3) Calcifications in the tumor,

4) Hyperostosis or degeneration of cranial bones near tumor attachment,

5) Tumor infiltrations towards the sella turcica,

6) Tumor position with respect to the circle of Willis.

The post-operative assessments included:

1) The extent of tumor resection,

2) Damage to the hypothalamic-pituitary system

\section{Endocrine assessment}

All patients qualified for operation underwent endocrine tests to evaluate the hypothalamic-pituitary axis function both before and after the procedure (1 day and 3-4 months following surgery). We focused primarily on: 1) finding any evidence of diabetes insipidus (24-hour urine collection, urine specific gravity and osmolality in $\mathrm{mOsm} / \mathrm{kgH}_{2} 0$ ), 2) measuring blood cortisol level to evaluate corticotropic function, 3) TSH, fT3, and fT4 to evaluate thyreotropic function.

\section{Methods of qualification for surgery}

After a clinical assessment and MRI evaluation, the patients were qualified to undergo surgery via the unilateral subfrontal approach

\section{Anesthesiology}

All patients were placed under general anesthesia according to standard neuroanesthesiologic practice with a focus on adequate cerebral perfusion and oxygenation. Therefore, total intravenous anesthesia (TIVA) was preferred for these procedures. As always, the patients were monitored (as dictated also by their general condition), which included electrocardiography, capnometry, pulse oximetry, as well as non-invasive, and direct blood pressure monitoring. Routine practice included the use of two intravenous lines.

\section{Surgical procedure}

All patients were operated on via a unilateral subfrontal approach. The medial part of the Sylvian fissure was routinely opened to drain the cerebrospinal fluid (CSF). After identification of the ipsilateral optic nerve (it was stretched by the tumor and appear in all cases), the internal carotid artery and precommunicating segment of the anterior cerebral artery (ACA), the blood supply to the tumor from the dura of the anterior fossa and tuberculum sellae was interrupted. Then, the tumor capsule was carefully microsurgically dissected from the optic nerves, chiasm, carotid arteries, and pituitary stalk after internal decompression of the tumor with cavitron ultrasonic surgical aspirator and bipolar cautery. The tumor was also removed from the ipsilateral optic canal after its unroofing. Tumor resection was completed after identification and preservation of the postero-laterally displaced pituitary stalk. Finally, the basal dura (dural attachment) was removed and any enostosis on the limbus sphenoidale were drilled out. The tumor was totally removed in all cases (Simpson Grade I or II). The pieces of resected tumor were fixed in 10\% formalin for the pathological examination.

\section{Intraoperative assessment}

The extent of tumor resection was assessed with the Simpson grading scale:

I- Macroscopically complete tumor resection, with excision of its dural attachment and any adjacent abnormal bone;

II- Macroscopically complete tumor resection with coagulation of its dural attachment,

III- Macroscopically complete removal of the tumor without resection (or coagulation) of its dural attachment,

IV- Partial removal of the tumor,

V- Tumor biopsy

\section{Histopathological assessment}

The resected tumor fragments were preserved for a histopathological examination. The examination was conducted at the Pathomorphology Laboratory. Histopathology examinations were routinely performed according to the WHO classification, with immunohistochemical evaluation of meningioma diagnostic markers i.e.: epithelial membrane antigen (EMA), CK (cytokeratins), S-100, glial fibrillary acidic protein (GFAP), carcinoembryonic antigen (CEA), CD43, Vimentin. The material to be assessed under a light microscope was fixed in a $4 \%$ solution of formaldehyde in water with phosphate buffer (fixing agent $\mathrm{pH} 7.2$ ).

\section{Statistical analysis}

The statistical analysis was conducted with Statistica 10.0. The data collected for the group were measured directly, constituting either objective or subjective aspects of the assessment. In two cases, the assessed variable values were altered:

1. Tumor volume was measured as the volume of an ellipsoid based on the tumor size graphed onto an X,Y,Z coordinate system, and calculated with the formula, where a,b,c represented half-axes of the ellipsoid;

2. Outcome was determined based on the sum of variables: Visual Acuity Outcome, Visual Field Outcome, Pituitary Function Outcome. 

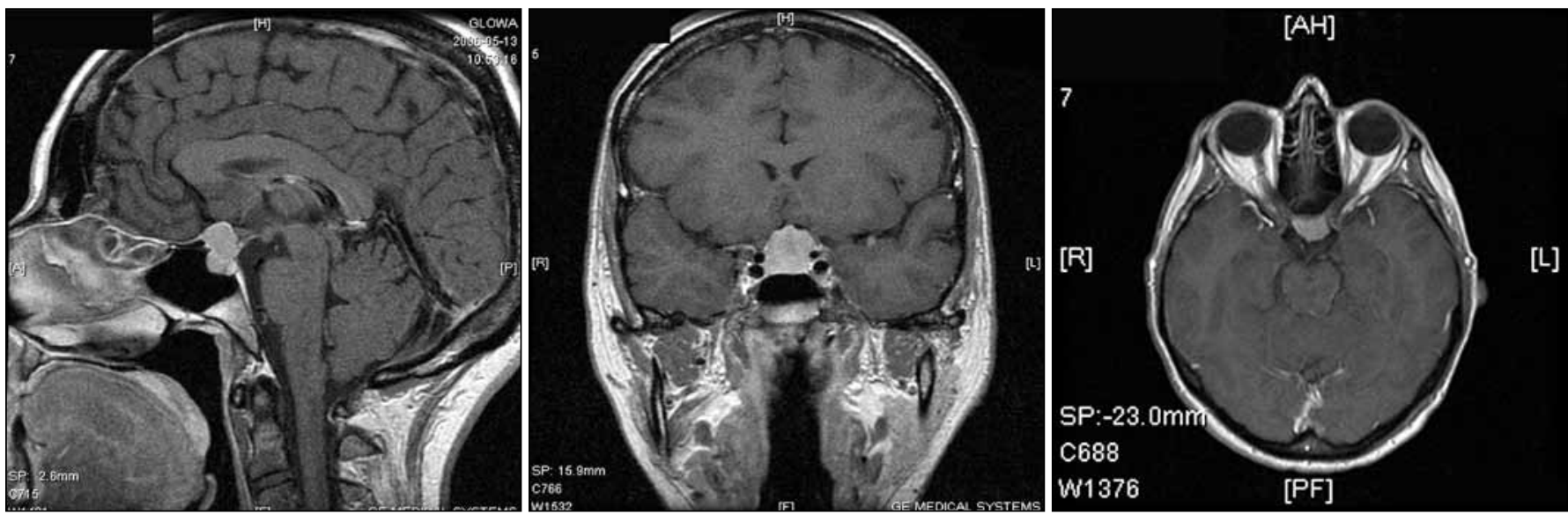

Figure 1: Magnetic resonance images of the tuberculum sellae meningioma prior to surgical treatment (1-300, 2-300, 3-300).

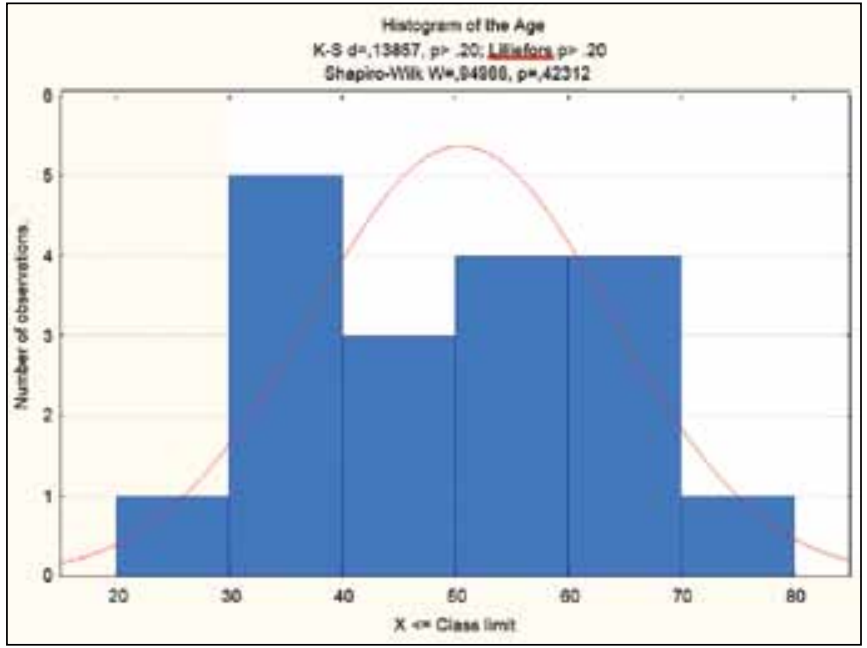

Figure 2: Histogram of the Age variable.

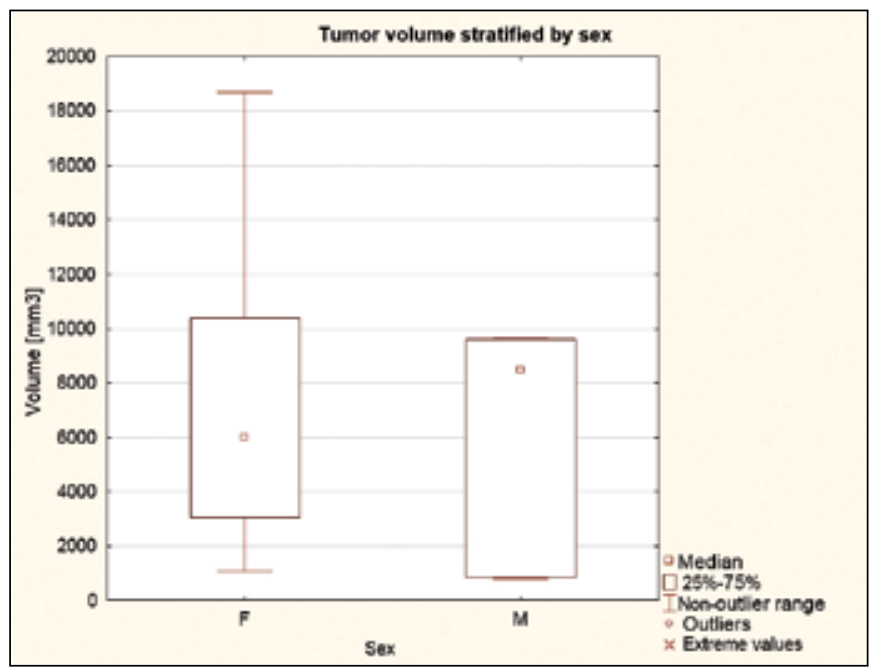

Figure 4: Tumor volume stratified by sex.

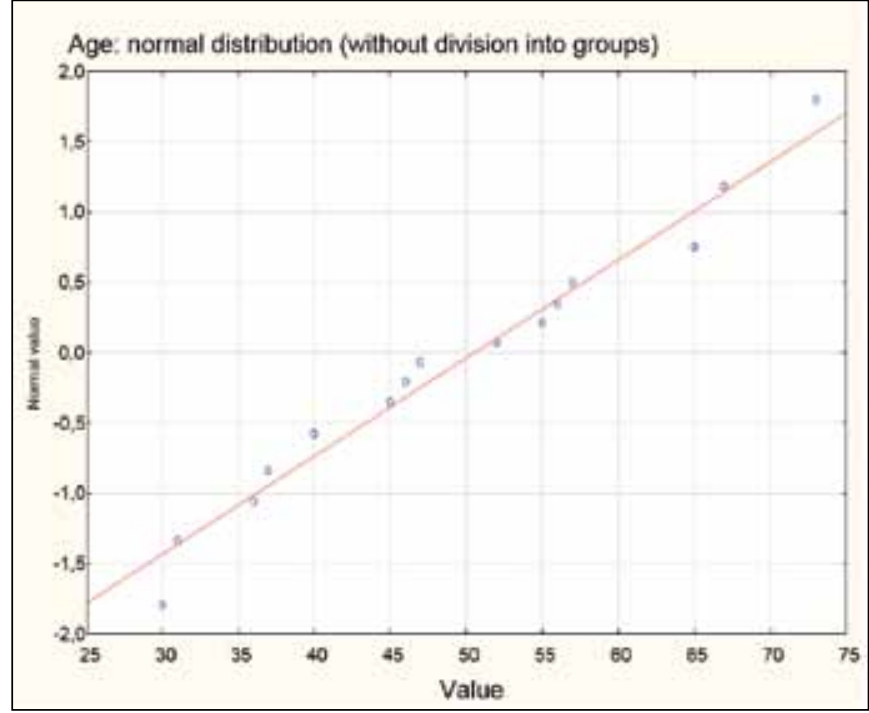

Figure 3: Normal distribution of the Age variable.

The following statistical tests were used: the Shapiro-Wilk test, Kolmogorov-Smirnov test, and Pearson's (linear) correlation coefficient.

\section{RESULTS}

All surgery results have been presented in Table III.

\section{Clinical assessment results}

There were significantly more women than men in the evaluated group. The female-to-male ratio was 15:3. The age of study participants ranged from 30 to 73 years, with a mean age of 50.5 years $(S D \pm 13.4)$. Apart from visual disturbances, four patients (all female) reported headaches. After surgical treatment, the headaches subsided in three out of four patients and changed its character in one patient.

The distribution of the age variable in this group was assessed with a histogram for the Age variable (Figure 2) and the Shapiro-Wilk test. 
Considering the fact that the Shapiro and Wilk's W statistic was not statistically significant, there were no grounds to reject the hypothesis stating that distribution of the Age variable is not consistent with normal distribution. This conclusion was also confirmed by a normal distribution graph for this variable (Figure 3).

\section{Neuroradiological assessment results}

Tumor size was analyzed in all patients and stratified by sex. Tumors were divided into three groups depending on their size:

a) From 0 to $2 \mathrm{~cm}$ - in 3 patients ( 2 females and 1 male)

b) From 2 to $4 \mathrm{~cm}$ - in 15 patients (13 females and 2 males)

c) Over $4 \mathrm{~cm}$ - in 0 patient

The volume of the tumor was also evaluated in the entire study group, stratified by sex (Figure 4 and Table IV). Three patients had tumor volume in the $0-6,000-\mathrm{mm}^{3}$ range; 4 patients - in the $6,001-\mathrm{mm}^{3}-12,000-\mathrm{mm}^{3}$ range; and in 11 patients tumor size exceeded $>12,000-\mathrm{mm}^{3}$.

Tumors found in female patients tended to be larger. However, the differences in tumor size (volume) between the female vs. male groups were not statistically significant.

\section{Results of assessing visual disturbances}

All patients were diagnosed with visual disturbances before their surgery, with two patients (2 females) reporting exclusively visual acuity abnormalities and two ( 1 female and 1 male) reporting exclusively field of vision abnormalities. The most common visual field defect was bitemporal hemianopsia, diagnosed in 10 patients. Four patients were diagnosed with mono-ocular (right) temporal hemianopsia and two with mono-ocular (left) temporal hemianopsia. Vision improved in all patients in the post-operative period versus

Table III: Results of Surgery

\begin{tabular}{|c|c|c|c|c|c|c|c|c|c|c|c|}
\hline \multirow{3}{*}{$\begin{array}{l}\text { Pt } \\
\text { No. }\end{array}$} & \multirow{3}{*}{$\begin{array}{c}\mathrm{Pt} \\
\text { Initials }\end{array}$} & \multirow{3}{*}{$\begin{array}{c}\text { Age } \\
\text { (years) }\end{array}$} & \multirow[b]{3}{*}{ Sex } & \multirow{3}{*}{$\begin{array}{l}\text { Extent } \\
\text { of the } \\
\text { operation } \\
\text { (Simpson } \\
\text { grade) }\end{array}$} & \multicolumn{5}{|c|}{ Surgery results } & \multirow{3}{*}{$\begin{array}{l}\text { Histological } \\
\text { diagnosis }\end{array}$} & \multirow{3}{*}{$\begin{array}{c}\text { Post- } \\
\text { operative } \\
\text { follow-up in } \\
\text { months. }\end{array}$} \\
\hline & & & & & \multicolumn{2}{|c|}{ vision } & \multicolumn{3}{|c|}{ Pituitary endocrine function } & & \\
\hline & & & & & acuity & FOV & $\begin{array}{l}\text { Diabetes } \\
\text { insipidus }\end{array}$ & $\begin{array}{l}\text { Cortico- } \\
\text { tropic } \\
\text { function }\end{array}$ & $\begin{array}{l}\text { Thyreo- } \\
\text { tropic } \\
\text { function }\end{array}$ & & \\
\hline 1 & LS & 45 & $\mathrm{~F}$ & 2 & 1 & 1 & 0 & 0 & 0 & MM & 39 \\
\hline 2 & WJ & 67 & $\mathrm{~F}$ & 2 & 1 & 1 & 0 & 0 & 0 & PM & 35 \\
\hline 3 & IJ & 73 & $\mathrm{~F}$ & 2 & 1 & 1 & 0 & 0 & 0 & TM & 34 \\
\hline 4 & IB & 37 & $\mathrm{~F}$ & 2 & 1 & 0 & 0 & 0 & 0 & MM & 33 \\
\hline 5 & BT & 65 & $\mathrm{~F}$ & 2 & 1 & 1 & 0 & 0 & 0 & MM & 32 \\
\hline 6 & $A D$ & 56 & $\mathrm{~F}$ & 2 & 1 & 0 & 0 & 0 & 0 & MM & 30 \\
\hline 7 & $\mathrm{JP}$ & 67 & $\mathrm{~F}$ & 2 & 1 & 1 & 0 & 0 & 0 & MM & 26 \\
\hline 8 & $W t$ & 55 & $\mathrm{~F}$ & 2 & 1 & 1 & 0 & 0 & 0 & PM & 22 \\
\hline 9 & LT & 46 & $M$ & 2 & 0 & 1 & 0 & 0 & 0 & TM & 15 \\
\hline 10 & EK & 30 & $\mathrm{~F}$ & 2 & 1 & 1 & 0 & 0 & 0 & MM & 17 \\
\hline 11 & $\mathrm{KL}$ & 40 & $\mathrm{~F}$ & 2 & 0 & 1 & 0 & 0 & 0 & MM & 17 \\
\hline 12 & $\mathrm{RP}$ & 52 & $M$ & 2 & 1 & 1 & 0 & 0 & 0 & MM & 19 \\
\hline 13 & IT & 36 & $\mathrm{~F}$ & 2 & 1 & 1 & 0 & 0 & 0 & MM & 11 \\
\hline 14 & JP & 57 & $\mathrm{~F}$ & 2 & 1 & 1 & 0 & 0 & 0 & MM & 10 \\
\hline 15 & JK & 40 & $\mathrm{~F}$ & 2 & 1 & 1 & 0 & 0 & 0 & MM & 10 \\
\hline 16 & 10 & 65 & $M$ & 2 & 1 & 1 & 0 & 0 & 0 & MM & 8 \\
\hline 17 & MW & 31 & $\mathrm{~F}$ & 2 & 1 & 1 & 0 & 0 & 0 & MM & 6 \\
\hline 18 & US & 47 & $\mathrm{~F}$ & 2 & 1 & 1 & 0 & 0 & 0 & MM & 6 \\
\hline
\end{tabular}

The extent of the operation (Simpson grade): 1- macroscopically complete tumor resection, with excision of its dural attachment and any adjacent abnormal bone; 2- macroscopically complete tumor resection with coagulation of its dural attachment, 3-Macroscopically complete tumor removal without resection of its dural attachment, 4-Partial tumor removal, 5-Tumor biopsy. Post-operative visual acuity: -1-worsening; 0-no change;1-improvement; Post-operative field of vision (FOV): -1-worsening; 0-no change; 1-improvement; Post-operative pituitary function: diabetes insipidus -1-worsening, 0-no improvement; 1-improvement; corticotropic function -1-worsening, 0-no change, 1-improvement; thyreotropic function -1-worsening, 0-no change, 1-improvement; Histopathological diagnoses: MM - meningothelial meningioma; PM psammomatous meningioma; TM - transitional meningioma. M: Male, F: Female, Pt: Patient. 
Table IV: Tumor Volume in $\mathrm{mm}^{3}$ in the Total Study Group, and Stratified by Sex

\begin{tabular}{cccccccc}
\hline & Sex & valid N & Mean & Minimum & Maximum & SD \\
\hline Volume & F & 15 & 7035.98 & 1072.33 & $18,692.48$ & 4708.25 \\
\hline Volume & M & 3 & 6310.94 & 816.81 & 9621.13 & 4791.26 \\
\hline Volume & Total & 18 & 6915.14 & 816.81 & 18692.48 & 4586.25 \\
\hline
\end{tabular}

M: Male, F: Female.

Table V: Tabularized Correlation Coefficients for Pre-Operative Variables

\begin{tabular}{ll}
\hline & Tumor volume \\
\hline Headache & 0.243832897 \\
\hline Visual acuity disturbances & 0.416712118 \\
\hline Field of vision disturbances & 0.037005 \\
\hline Duration of visual anomalies & 0.009650 \\
\hline
\end{tabular}

Without division into groups; Correlations between symptoms and tumor volume. The resulting correlation coefficients are significant, with $p<0.05, N=18$ (Cases with missing data were not considered).

Table VI: Correlation Coefficients for Post-Intervention Variables

\begin{tabular}{lc}
\hline & Tumor volume \\
\hline Visual Acuity Outcome & 0.416712 \\
\hline Visual Field Outcome & -0.097588 \\
\hline Result & 0.291421 \\
\hline
\end{tabular}

Correlations The correlation coefficients are significant, with $p$ $<0.05000$. $N=18$ (Cases with missing data were not considered).

Table VII: Patients Stratified According to the Histopathological Diagnosis

\begin{tabular}{lccc}
\hline & Number & Cumulative & $\%$ \\
\hline $\begin{array}{l}\text { Meningothelial } \\
\text { meningioma }\end{array}$ & 14 & 14 & 77.78 \\
\hline $\begin{array}{l}\text { Psammomatous } \\
\text { meningioma }\end{array}$ & 2 & 16 & 11.11 \\
$\begin{array}{l}\text { Transitional } \\
\text { meningioma }\end{array}$ & 2 & 18 & 11.11 \\
\hline Missing data & 0 & 18 & 0.00000 \\
\hline
\end{tabular}

their pre-operative status. There were no exacerbations in visual disturbances in any of the patients.

Although an analysis of statistical variables prior to surgical intervention revealed no statistically significant differences, it indicated intra-group correlations. Table $\mathrm{V}$ presents the results of this analysis.

The results showed a correlation between visual acuity disturbances and tumor volume as well as between headaches and tumor volume in the evaluated population. These intervariable correlations were not statistically significant. No correlations were demonstrated for the remaining variables.

Similar analyses were conducted for post-operative variables.

The results are presented in Table VI.

Analysis results indicated the existence of a slight correlation between tumor volume (size) and visual acuity results. This indicates that removal of an objectively larger tumor may be associated with greater expectations as to improvement in visual acuity. A similar, though weaker still, correlation was observed between the value of the Outcome variable and tumor volume. However, given the fact that these correlations were not statistically significant, they should not be subject to generalization but rather should be treated as an indicator in analyzing larger study groups.

\section{Endocrine assessment results}

In the pre-operative period, no patients presented symptoms of diabetes insipidus, or any abnormalities in corticotropic or thyreotropic pituitary function as manifestations of tuberculum sellae meningioma. A similar lack of pituitary abnormalities was observed post-operatively, with no patients having developed diabetes insipidus or cortico-/thyreotropic pituitary dysfunction.

\section{Histological assessment results}

Histopathological examinations of the resected tumors revealed only 3 meningioma subtypes: a) meningothelial, b) psammomatous, and c) transitional meningioma (Table VII).

The most commonly diagnosed (in 12 females and 2 males [77\%]) subtype of meningioma was meningothelial meningioma. Psammomatous meningioma was diagnosed in 2 females (11\%) and transitional meningioma in 1 female and 1 male (11\%). Post-operative follow-up revealed no cases of tumor recurrence, thus we were unable to compare these histological findings to those in recurrent tumors.

\section{DISCUSSION}

The first case of tuberculum sellae meningioma was reported by J. Steward, based on a postmortem examination in 1899. In 1916, H. Cushing conducted the first complete removal of this tumor. In 1938, Cushing and Eisenhardt presented a series of 28 tuberculum sellae meningiomas and proposed their classification based on tumor size. They also introduced the term "suprasellar chiasmal syndrome" describing the clinical course of this tumor, which allowed 


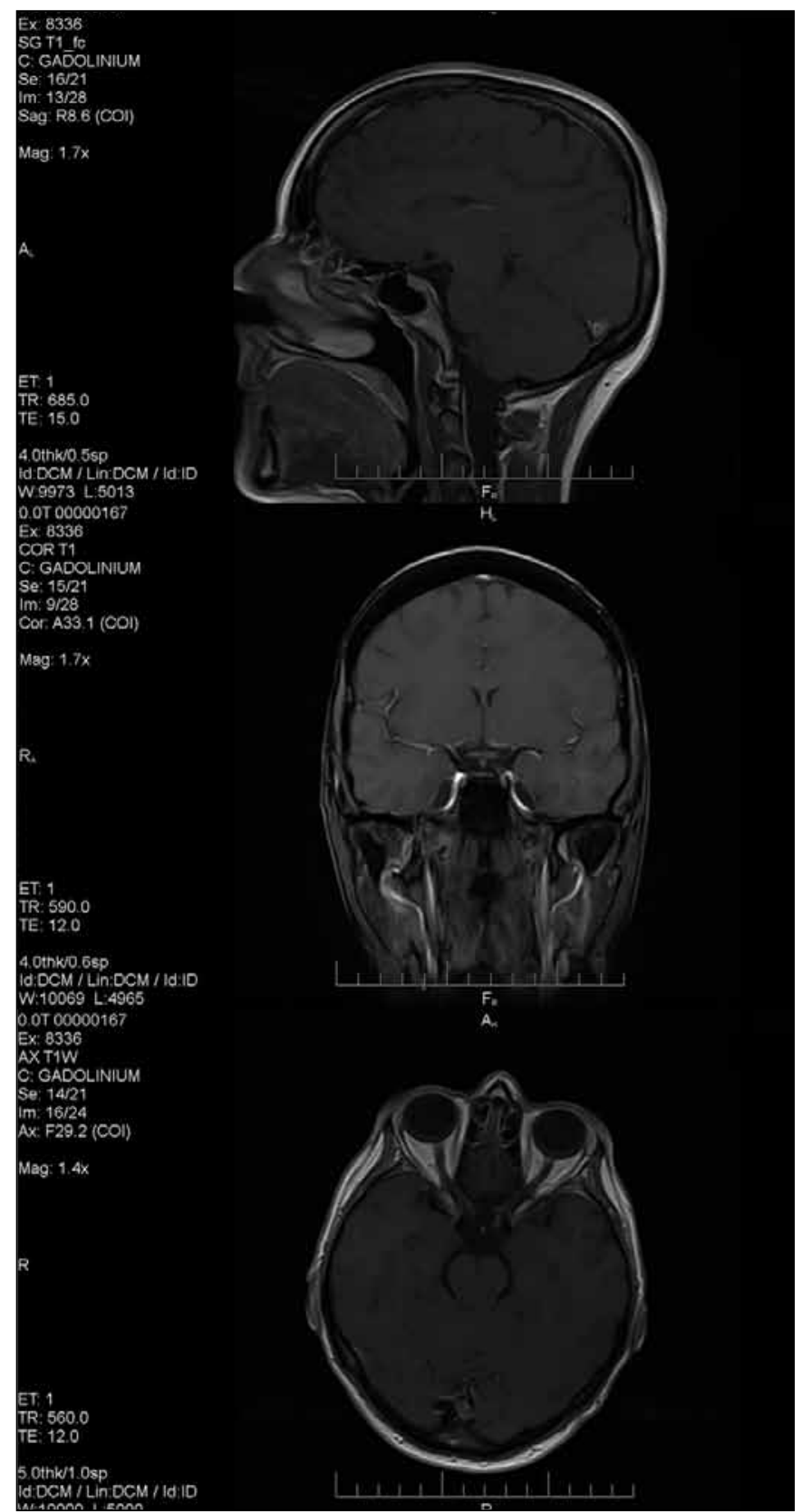

Figure 5: Post-operative magnetic resonance images of tuberculum sellae meningioma (11-300,13-300,14-300).

for its differentiation from other tumors of the region (pituitary adenomas, craniopharyngiomas and gliomas). Since then, a number of tuberculum sellae meningioma case series have been described in the literature reporting the results of surgical treatment. We presented an assessment of surgical treatment outcomes in 18 patients (i.e. 15 females [87\%] and 3 males [15\%] aged between 30 and 73 years (mean age: 50.5 ; standard deviation: 13.4 ; including 54.3 years in men and 49.7 in women) diagnosed with tuberculum sellae meningioma. According to Cushing and Eisenhardt, the mean age of patients diagnosed with central nervous system meningioma ranges from 42.9 years in females and 52 years in males (7). Fahlbusch and Schott (9) reported the mean age in affected females to be 54.3 years and that in affected males 54.9 years $(7,9,28)$. In the present study, a surgical approach was selected for each patient and all patients who qualified for surgery underwent unilateral subfrontal craniotomy, as this approach was considered safe. The extent of tumor removal in all patients was classified as Simpson grade II. We did not observe any deaths or significant post-operative complications (such as cerebrospinal fluid leakage, infections, or intracranial hematomas) in the group operated via the unilateral subfrontal approach. According to the available literature reports, the mortality rate in tuberculum sellae meningiomas ranges from $0 \%$ to $8.6 \%$. Interestingly, Nakamura et al. reported a correlation between mortality and the surgical approach used, with the following findings: frontal and pterional approach - $0 \%$, bifrontal approach - 9.5\% $(8,29)$. No deaths were observed in our study.

Tumor volume was also analyzed. The mean tumor volume was $6915.14 \mathrm{~mm}^{3}\left(7035.98 \mathrm{~mm}^{3}\right.$ in females and $6310.94 \mathrm{~mm}^{3}$ in males). The study group showed a correlation between tumor size and visual (acuity) abnormalities $(3,6,14,15)$. It was Rosenstein et al. (29) who confirmed more favorable surgical treatment outcomes in the case of tumors below $3 \mathrm{~cm}$ in diameter, with greater odds for visual improvement. Andrews and Wilson noticed that in the case of tumors measuring over $6 \mathrm{~cm}$ in diameter, the chance of visual improvement is significantly lower $(3,18)$.

We also analyzed visual disturbances - defects in visual field and visual acuity abnormalities prior to and after the operation. In the pre-operative period, visual acuity disturbances were observed in 16 patients (88\%), and field of view defects were also observed in 16 patients (88\%). We would like to emphasize that each patient had at least one type of visual disturbance. A study by Fahlbusch and Schott reported that $96 \%$ patients developed visual impairment as the first symptom of their disease. In our group, the pre-operative visual disturbances improved in all patients following the operation. No patient experienced further visual impairment whether field of view or acuity. In 2 patients $(12 \%, 1$ male and 1 female) visual acuity did not change, and 16 patients (88\%) experienced visual acuity improvement. In terms of visual field defects, no change was observed in two patients $(12 \%$; 2 females) and improved field of view was observed in 16 patients $(88 \%)$. Similar findings were reported by Mathiesen and Kihlstrom in a group of 29 patients (16). In that study, 91\% of patients experienced postoperative visual improvement. Somewhat less favorable results were described by Otanii et al. who reported visual field improvement in only $78 \%$ of 32 operated patients $(2,11,20)$. Conversely, Fahlbusch and Schott reported no visual improvement in $36 \%$ of patients in their group of 47 , and postoperative exacerbation in the existing visual acuity and field of view impairment in $20 \%$ of patients. Nakamura et al. reported an improvement in vision in $65 \%$ of 72 operated patients, and particularly emphasized that the surgical procedures conducted via lateral supraorbital access yielded vision improvement in $77.8 \%$ of patients. Bifrontal craniotomy yielded poorer results at $46.2 \%$ - still, this approach is used only in large tumors. However, Romani 
et al., who had used the lateral supraorbital approach, confirmed visual improvement in $52 \%$ out of 52 patients, with no improvement observed in $31 \%$ patients, and postoperative visual deterioration - in $2 \%(1,13,24,26,27)$. The rate of visual improvement in the presented literature ranges from $19 \%$ to $91 \%$ of operated patients, and the rate of visual deterioration ranges from $3 \%$ to $39 \%$. These findings indicate that surgical treatment via frontal craniotomy is associated with a significant visual improvement versus the preoperative status. We also evaluated the duration of visual disturbances. Our data was collected by means of a questionnaire completed by patients on a voluntary basis. Thus, these assessments were very subjective, as patients frequently failed to assign much significance to their early symptoms of visual impairment, treating them as part of the natural course of life. In reality, it was the emergence of subsequent clinical manifestations of the tumor that allowed for estimating the duration of visual disturbance history. The history of visual disturbances ranged from 1 to 36 months, with a mean of 14 months.

Our study included also an evaluation of endocrine pituitary function based on possible manifestations of diabetes insipidus, as well as corticotropic and thyreotropic function prior to, and after, surgery. Romani et al. reported endocrine disturbances in $10 \%$ out of their 42 patients (26). Recent literature in the field has seen an increased incidence of reported endocrine disturbances ranging from $2 \%$ to $43 \%$. Our study group demonstrated no hormonal abnormalities either prior to or after the surgery. Apart from our study, a study by Fahlbusch and Schott including 43 patients who qualified to undergo hormonal tests (from a group of 47) was the only one to show no evidence of diabetes insipidus in this type of tumor either before or after surgery. We would like to stress that some patients were receiving long-term hormone replacement therapy prior to surgery and were euthyreotic until the time of the procedure, having been endocrinologically prepared for surgery (9).

We also analyzed histopathological findings, as they play a significant role in scheduling post-operative follow-up visits and possible referrals for radiotherapy. Fahlbusch and Schott (9) demonstrated in a group of 47 patients that $79 \%$ were cases of meningothelial meningioma and $11 \%$ represented transitional meningioma. Our study also showed a greater incidence of meningothelial (14 patients [77\%]; 12 females and 2 males) and transitional meningioma (in 2 patients [12\%]; 1 female and 1 male). These two tumor types constituted $89 \%$ of all meningiomas in the evaluated patients.

Our findings suggest certain correlations between the preand the post-operative groups; however, these correlations must not be generalized. This may change when findings from a larger study group become available. Tumor location, with its proximity to the pituitary, suggests that, in a larger study group, surgical interventions in this region may have a discernible effect on pituitary function. The seeming lack of effects on the pituitary endocrine function may be amended in the future, as more pituitary hormones are considered and evaluated. Our studies continue.

\section{CONCLUSIONS}

1. Surgical treatment of tuberculum sellae meningiomas via unilateral frontal craniotomy is a safe technique with no significant complications.

2. Visual improvement was reported in $88 \%$ of the operated patients.

3. No pre- or post-operative endocrine disturbances were observed in patients operated via the supraorbital approach, which suggests that surgical treatment of tuberculum sellae meningiomas has no effect on pituitary endocrine function.

\section{- REFERENCES}

1. Akutsu H, Kreutzer J, Fahlbusch $R$, Buchfelder $M$ : Transsphenoidal decompression of the sellar floor for cavernous sinus meningiomas. Experience with 21 patients. Neurosurgery 65(1): 54-62, 2009

2. Al-Mefty O, Holoubi A, Rifai A, Fox JL: Microsurgical removal of suprasellar meningiomas. Neurosurgery 16: 364-372, 1985

3. Andrews BT, Wilson CB: Suprasellar meningiomas: The effect of tumor location on postoperative visual outcome. $J$ Neurosurg 69: 523-528,1988

4. Annegers JF, Laws ER, Kurland LT, Grabow J: Head trauma and subsequent brain tumors. Neurosurgery 4: 203-206, 1979

5. Borovich B, Doron Y: Recurrence of intracranial meningiomas: the role played by regional multicentricity. J Neurosurg 64: 5863, 1986

6. Couldwell WT, Weiss MH, Rabb C, Liu JK, Apfelbaum RI, Fukushima T: Variation of the standard transsphenoidal approach to the sellar region with emphasis on the extended approaches and parasellar approaches: Surgical experience in 105 cases. Neurosurgery 55: 539-550, 2004

7. Cushing H, Eisenhardt L: Meningiomas: Their Classification, Regional Behavior, Life History and Surgical End Results. Illinois:Springfield, 1939: 224-249

8. De Divitis O, de Divitis E: Anterior cranial fossa meningiomas. A new surgical perspective. World Neurosurg 77: 713-724, 2012

9. Fahlbusch R, Schott W: Pterional surgery of meningiomas of the tuberculum sellae and planum sphenoidale: Surgical results with special considerations of ophthalmological and endocrinological outcomes. J Neurosurg 96: 235-243, 2002

10. Fatemi N, Dusick JR, de Paiva Neto MA: Endonasal versus supraorbital keyhole removal of craniopharyngiomas and tuberculum sellae meningiomas. Neurosurgery 64:269-287, 2009

11. Galal A, Faisal A, Al-Werdany M, El Shehaby A, Lotfy T, Moharram H: Determinants of postoperative visual recovery in suprasellar meningiomas. Acta Neurochir 152: 69-77, 2010

12. Humphreys DH, Schwartz MR, Jenkins HA: Meningioma a case of transcranial recurrence managed by base-of-skull technique and review of the tumor. Otolaryngol Head Neck Surg 93(4): 563-570, 1988

13. Kelly DF, Dusick J, Fatemi N: Response. Surg Neurol 72(6): 644-646, 2009 
14. Lindley T, Jeremy DW: Minimally invasive surgery (endonasal) for anterior fossa and sellar tumors. Neurosurg Clin N Am 21: 607-620, 2010

15. Mahmoud M, Nader R, Al-Mefty O: Optic canal involvement in tuberculum sellae meningiomas. Neurosurgery 67: 108-119, 2010

16. Mathiesen T, Kihlstrom K: Visual outcome of tuberculum sellae meningiomas after extradural optic nerve decompression. Neurosurgery 59: 57-576, 2006

17. Modan B, Baidatz D, Mart H, Steinitz R, Levin SG: Radiationinduced head and neck tumours. Lancet 1(7852):277-279, 1974

18. Nakamura M, Roser F, Struck M, Vorkapic P, Samii M: Tuberculum sellae meningiomas: Clinical outcome considering different surgical approaches. Neurosurgery 59: 1019-1029, 2006

19. Nozaki K, Kikuta K, Takagi Y, Mineharu Y, Takahashi JA, Hashimoto N: Effect of early optic canal unroofing on the outcome of visual functions in surgery for meningiomas of the tuberculum sellae and planum sphenoidale. Neurosurgery 62(4):839-846, 2008

20. Otani N, Muroi C, Yano H, Khan N, Pangalu A, Yonekawa Y: Surgical management of tuberculum sellae meningioma: Role of selective extradural anterior clinoidectomy. $\mathrm{Br} \mathrm{J}$ Neurosurg 20(3):129-138, 2006

21. Puchner M, Fischer-Lampstis RC, Herrmann HD, Freckman N: Suprasellar meningiomas-neurological and visual outcome at long -term follow up in homogeneous series of patiens treated microsurgically. Acta Neurochir 140: 1231-1238, 1998

22. Park CK, Jung HW, Yang SY, Seol HJ: Surgically treated treated tuberculum sellae and diaphragm sellae meningiomas: The importance of the short-term visual outcome. Neurosurgery 59: 238-243, 2006
23. Rachlin JR: Meningiomas. Neurosurgery 57: 7-35, 1991

24. Reubi JC, Maurer R, Klijn JG, Stefanko SZ, Foekens JA, Blaauw G, Blankenstein MA, Lamberts SW: High incidence of somatostatin receptors in human meningiomas: Biochemical characterization. J Clin Endocrin Metab 63: 433-438, 1986

25. Rohringer M, Sutherland GR, Louw DF, Sima AAF: Incidence and clinicopathological features of meningioma. J Neurosurg 71: 665-672, 1989

26. Romani R, Laakso A, Kangasniemi M, Niemela M, Hernesniemi $\mathrm{J}$ : Lateral supraorbital approach applied to tuberculum sellae meningiomas: Experience with 52 consecutive patients. Neurosurgery 70: 1504-1519, 2012

27. Romani R, Lehecka M, Gaal E, Toninelli S, Celik O, Niemelä M, Porras M, Jääskeläinen J, Hernesniemi J: Lateral supraorbital approach applied to olfactory groove meningiomas: experience with 66 consecutive patients. Neurosurgery 65: 39-53, 2009

28. Rosenstein J, Symon L: Surgical management of suprasellar meningioma. Part 1: The influence of tumor size, duration of symptoms, and microsurgery on surgical outcome in 101 consecutive cases. J Neurosurg 61: 633-641, 1984

29. Rosenstein J, Symon L: Surgical management of suprasellar meningioma. Part 2: Prognosis for visual function following craniotomy. J Neurosurg 61: 642-648, 1984

30. Solero CL, Giombini S, Morello G: Suprasellar and olfactory meningiomas. Raport on a series of 153 personal cases. Acta Neurochir 67:181-194,1983

31. Zevgaridis D, Medele RJ, Müller A, Hischa AC, Steiger HJ: Meningioma of the sellar region presenting with visual impairment: Impact of various prognostic factors on surgical outcome in 62 patients. Acta Neurochir (Wien) 143:471-476, 2001 